\title{
Dual Language Programme (DLP) in Bintulu District, Sarawak Primary Schools: Discovering Teachers' Perception towards Curriculum Change
}

\author{
Audrey Shalini Ananthan, Nur Ehsan Mohd Said
}

\begin{abstract}
Malaysian Education Blueprint (2013-2025) clearly stated that one of the pupils' requirements is to have bilingual skills; to develop qualified pupils in Bahasa Malaysia as a national language and as a medium of unity; and English as an foreign language of communication; A very limited number of studies has been done to investigate the perception of Malaysian teachers towards Dual Language Programme (DLP) with regards to this curriculum change. Thus, this study is designed to (i) identify the perception of teachers towards the implementation of Dual Language Program (DLP), and (ii) investigate the factors that affects the implementation of Dual Language Programme (DLP) in primary schools in Bintulu. Sixty Malaysia DLP Science and Mathematics teachers were given a questionnaire survey to fill in. Semi-structured interviews were carried out among the teachers as well. The data showed that teachers have positive feedbacks towards their perceptions on skills, interest and knowledge in DLP. There are 3 main factors that affects the implementation of DLP in schools, pupils' ability, workload and time constrain, and insufficient facilities, materials and resources.
\end{abstract}

Index Terms-Dual Language Programme, Teachers, Perceptions, Curriculum Change, Primary Schools.

\section{INTRODUCTION}

English has become a major language commonly used in the world. In Malaysia, English is the second language because of its significance in culture, politics, economics and technology (Bullah \& Yunus, 2018). The British Council projects that by 2020 two billion people in the world will be studying English (Smith et. al, 2019). Learning English is important as it enables you to communicate easily with your fellow global citizens (Nair et., 2014).

The Ministry of Education (MOE) emphasizes the significance of English language benefit in education policy and preparation. There are several initiatives and reforms in the education policies that have been introduced to date simultaneously to provide incentives for students to get educated and learn the language, as well as to improve their English skills.

In 2003, MOE transformed the education system by using English in the teaching of Science and Mathematics (PPSMI) in all schools in Malaysia. The PPSMI policy was introduced by Mahathir Mohamad, as the Prime Minister of Malaysia in

Audrey Shalini Ananthan, Faculty of Education National University of Malaysia (UKM) 43600, Bangi, Selangor, Malaysia

Nur Ehsan Mohd Said, Lecturer at Faculty of Education National University of Malaysia (UKM) 43600, Bangi, Selangor, Malaysia.
2003, based on a decision made in a special meeting of the Cabinet on July 19, 2002 (Gill, 2012). The main intentions of this transformation were to encourage the use of English language among the Malaysian students and to prepare them to compete globally.

However, there was a major concern among high government officials and employers on the lack of ability of the graduates to speak in English. Due to its sudden implementation, it was believed that teachers were not fully occupied with the skills and knowledge and caused some controversies were raised. The recognition of students, the abilities and expertise of instructors, and the success of pupils and the approval of communities have been discussed for years. In 2012 the former Minister of Education, after debating the pros and cons of PPSMI, declared the removal of PPSMI.

Malaysian Education Blueprint 2013-2025 (MEB) was created by the government to ensure to progress of our education in Malaysia continues to grow and has relevant standard internationally. In 2016, the Ministry of Education came up with DLP to address the demands of globalization. It was an action system under Inspiring Bahasa Malaysia and Improving English (MBMMBI) where DLP is applied in English-language teaching in math and science. The goal of the program is to allow students to access and explore a broad spectrum of information in order to compete internationally, to increase their English skills and to enhance potential employability prospects for pupils (Soule and Warrick, 2015). In the early stages of the implementation of DLP, there are few criteria that schools have to fulfil stated by the ministry. The school requirements for adopting DLP are that the schools require sufficient funding, the Principal or Headmaster and teachers are able to adopt DLP, parent desire and encouragement, and the school achievement in Bahasa Malaysia should be on par (Suliman, et. al , 2018).

Sarawak is a state in Malaysia that has more than 20 languages spoken and English is not one of them (Ting, 2003). As in Bintulu, Indigenous people (Iban, Malay, Melanau, Kenyah, Kayan, Punan and Bidayuh) accounted for the largest portion of the town population, followed by Chinese people. While Iban language is widely used in Bintulu, there is less opportunity given to families, especially students to communicate in English except for in schools. In Bintulu District itself, there are 18 primary schools (Sekolah Kebangsaan) who are involve in the implementation of DLP in Year 1.

As for that, over the last period, there are numbers of 


\section{Dual Language Programme (DLP) in Bintulu District, Sarawak Primary Schools: Discovering Teachers' Perception Towards Curriculum Change}

research on Dual Language Programs (DLP) conducted especially in non-native English-speaking countries such as Malaysia, Vietnam, India and Thailand. This important trend towards improving the mastery of the English language by students through DLP occurs as English has received nearly equal attention among other languages, especially in the professional setting due to its distinct significance and relevance in the current era of globalisation (Nasri, et. al, 2018).

\section{LITERATURE REVIEW}

\section{A. Second Language Acquisition Theory}

The Second Language Acquisition Theory developed by Krashen (1982) who proposes that the second language acquisition theory forms part of theoretical linguistics; it can be studied and developed without regard to practical application Furthermore, language acquisition does not require extensive use of conscious grammatical rules and tedious drills. Krashen also claims that acquisition occurs whenever language skills are developed similar to how native speakers learn grammatical rules. If language skills are developed via formal instruction, this is referred to as learning.

Additionally, Krashen believes that acquisition requires meaningful interaction with the target language. This infers that speakers are concerned not with the form of utterances but with the understanding of the messages conveyed. The question arises whether humans learn the target language formally or acquire the language via meaningful conversation and by becoming immersed with speakers of the target language. Krashen proposes 5 hypotheses pertaining to the second language acquisition theory;

(i) the acquisition

(ii) the monitor hypothesis

(iii) the natural order hypothesis

(iv) the input hypothesis

(v) the affective filter hypothesis.

\section{B. Constructivism Learning Theory}

Constructivism is basically a theory which is based on observation and scientific study, about how people learn. It says that people develop their own view of the universe, by witnessing events and by focusing on certain experiences (Bada \& Olusegun, 2015). When we come upon anything different, we have to balance it with our past thoughts and observations, maybe modifying what we believe, or maybe discarding the latest knowledge as meaningless. In either event, we are involved, our own intelligence creators. To do that, we need to ask questions, investigate and evaluate what we know. The constructivist theory of learning may refer to a variety of various instructional methods inside the classroom. Typically, it involves enabling students to use constructive strategies (experiments, real-world problem-solving) to build more information and then focus on what they are learning and how their comprehension is evolving. The teacher ensures that he / she knows the pre-existing expectations of the students and directs the practice to tackle them, then expand on them (Lim \& Chai, 2004).

The origins of constructionism exist in theory, psychology, sociology, and culture. But although recognizing constructivism is important to students, it is also important to consider the consequences that this definition of learning has for instructor and instructor career growth (Tam, 2000). The core concept of Constructivism is that human thought is set up on the foundations of previous knowledge to establish fresh consciousness. Such understanding of learning stands in sharp contrast to one where learning is the passive transfer of information from one individual to another, a concept where comprehension is essential, not development. Two essential ideas circle the basic concept of a constructed awareness. Initially, learners develop new understandings from what they already learned.

Learners tend to the situations through knowledge from prior practice that determines what existing or changed skills they obtain from fresh learning experiences (Ertmer \& Newby, 1996). The second notion is that learning is not passive, nor aggressive. In terms of what they experience in the current learning setting, the learners question their comprehension. If what learners meet is inconsistent with their current understanding, they may change their understanding to accommodate new experiences. During this phase, learners remain active: introduce existing understandings, take notice of related elements in new learning experiences, evaluate the quality of prior and evolving information and, based on that assessment, change information (Phillips, 1995). According to Guiffrida (2005), constructivism learning theory is a philosophy which enhances students' logical and conceptual growth.

\section{Benefits of Learning Science and Mathematics in English}

English-language instruction in science and mathematics serves as an avenue, allowing graduates to navigate and develop information to succeed internationally and boost the marketability of graduates in the workforce. Additionally, they may improve their vocabulary by through the communication hours of the students to English.This program is aligned with Malaysian Education Blueprint (2013-2025) goals of producing students who are at least bilingual in Malay language and English.

Those students certainly assume that they know more than Bahasa Melayu in English. Yunus and Shukri (2017) thought that learning English-language mathematics and science would make their comprehension simpler than in Malay. Hence, it is believed that students will be able to perform better in the subject if they are given the opportunity to learn English language and they will definitely able to engage themselves with the language. Suliman, Nor and Yunus (2017) argued that ETeMS has a crucial role to play in the development of English-speaking students to keep pace with the rapid advances in science and technology.This programs undeniably establishes a high level of expertise in both languages. 
Besides that, students who joined this program will gain more vocabulary. Students in Malaysia have further interaction with other topics in Bahasa Melayu as it is the schools' mode of instruction. Reiterating that the purpose of introducing English as the instructional medium in mathematics and science teaching and learning is primarily to allow students to keep pace with developments in science and technology by enabling them to access this information, which is mainly available in English (Pandian and Ramiah, 2004). Through this program, the student will have better access to English language through Mathematics, Science and English. According to Lindholm-Leary and Hernandez (2011) most DLP students were rated as proficient in their two languages.

\section{METHODOLOGY}

\section{A. Research Design}

This study included a survey approach in which researchers obtained both quantitative (questionnaire) and qualitative (interview) data in order to examine teachers ' attitudes toward the adoption of DLP in urban primary schools and also to identify the factors affecting its implementation. The researcher may change data in many ways by using survey design for this study. When utilizing survey design for this analysis, the researcher can modify data in several ways to address research questions, and easily gather data (Piaw, 2016).

\section{B. Participants and Setting}

Data gathering is essential in research, as the data is meant to contribute to a better understanding of a theoretical framework. As for that, in determining research participants, the process on selecting suitable participants will be based on the questions of the study. In this study, purposive sampling will be chosen where the research participants will have to fulfil the aspects needed.

In other terms, the purposeful sampling method, often called decision sampling, is a participant's conscious preference regardless of the attributes which the participant possesses (Etikan, 2016). This includes recognizing and choosing knowledgeable and well-informed people or groups of people of a trend of concern (Creswell, 2011).

For the purpose of this research, sixty DLP science and mathematics teachers in Bintulu district were selected purposively as the research participants. The selection was on their willingness to get involved in the survey and interview.

\section{Instruments}

\section{Questionnaire}

Despite some modifications from the Kamlun (2005) and Ministry of Education (2002) reports, the questionnaire elements were revised to suit the objectives of this study. The questionnaire consisted of two sections: 1) demographic context and 2) their competencies and skills expectations. The first segment included 6 elements describing the history of the staff. The second section contained 27 items about their interest, skills and knowledge as well as the challenges that they faced in implementing DLP. The second segment uses 5-point Likert scale and 1 element open-ended. The open-ended element was intentionally designed to get the teachers ' views about what aspects influence their school's adoption of the DLP.

\section{Semi-Structure Interview}

This analysis has also made use of a collection of semi-structured interview questions. The aim of this interview interviewing was to get more details about the willingness of mathematics and science teachers to incorporate DLP. Teachers were asked in this semi-structured interview about their opinions on introducing DLP. It is mainly used to highlight the pattern on the factors that affects the implementation of DLP.

\section{Procedures}

Phase 1: Obtain permission from the Education District Officer

Before conducting this research, a letter was sent to Bintulu Education officer to obtain permission in conducting research in SK schools in Bintulu. An immediate email was given where the officer pleasingly allows the research to be done in the schools involved.

Phase 2: Obtain Permission from the school authorities Before conducting this survey, it is also vital to obtain the permission from the schools' administrators. Since 7 schools were involved, the researcher went to these 7 schools and met with the administrators. All school administrators allowed the research to be done which involved their Mathematics and Science teachers.

Phase 3: Preliminary meeting with the participants

The researcher conducted a preliminary meeting with the participants. It is to build rapport with the participants involved in the research. The meeting involved the confirmation of the date, time and location of the interview. The researcher explained the purpose of the study to the participants and they were informed that the interview session will be audio-recorded by the researcher. Thus, the researcher handed-over a consent letter to indicate the willingness of the participants to voluntarily be involved in this study. One hour was allocated for every interview session and will be recorded by using two recording devices: a laptop and an iPhone.

Phase 4: Data collection and analysis

The data from the questionnaire was collected via online by using Google form. The researcher gave a time period for the participants to answer the questionnaire and the results can be obtained immediately. As for the interview session, it was conducted face-to-face. The teachers were selected based on a purposive sampling which to help the researcher to get an insight of their readiness towards curriculum change. The data that collected were analyzed by using frequency and percentage, while the interview will be categorized and analyzed into themes. 


\section{DATA ANALYSIS}

A. Teachers' perception on interest towards DLP

\begin{tabular}{|c|c|c|c|c|c|c|c|}
\hline \multirow[t]{2}{*}{ No } & \multirow[t]{2}{*}{ Items } & SD & D & NAD & A & SA & \multirow[t]{2}{*}{ Mean } \\
\hline & & $(\%)$ & $(\%)$ & $(\%)$ & $(\%)$ & $(\%)$ & \\
\hline \multirow[t]{2}{*}{1} & English is an important & 0 & 1 & 8 & 18 & 33 & 4.41 \\
\hline & language. & $(0)$ & $(1.7)$ & (13.3) & $(30)$ & (55) & \\
\hline \multirow[t]{3}{*}{2} & It is easier to teach & 10 & 9 & 25 & 8 & 8 & 2.91 \\
\hline & Mathematics/Science in & $(16.7)$ & (15) & $(41.7)$ & (13.3) & (13.3) & \\
\hline & English. & & & & & & \\
\hline \multirow[t]{3}{*}{3} & I have fun teaching & 6 & 10 & 19 & 16 & 9 & 3.24 \\
\hline & Mathematics/Science in & (10) & $(16.7)$ & $(31.7)$ & $(26.7)$ & (15) & \\
\hline & English. & & & & & & \\
\hline \multirow[t]{3}{*}{4} & I must give exposure to pupils & 0 & 8 & 12 & 25 & 15 & 3.83 \\
\hline & in learning Mathematics & (0) & (13.3) & (20) & $(41.7)$ & $(25)$ & \\
\hline & Science in English. & & & & & & \\
\hline \multirow[t]{5}{*}{5} & Pupils have fun in learning & 6 & 12 & 21 & 16 & 5 & 3.01 \\
\hline & Mathematics/Science in & $(10)$ & $(20)$ & (35) & $(26.7)$ & (8.3) & \\
\hline & English. & & & & & & \\
\hline & Total & 22 & 40 & 85 & 83 & 70 & 3.49 \\
\hline & & (7.3) & $(13.3)$ & (28.3) & $(27.7)$ & (23.3) & \\
\hline
\end{tabular}

Most of the teachers have a stand that English is an significant language to be acquired by both teachers and pupils. This point is proven where $85 \%$ of the teachers believed that English is an import language (item 1). In addition to that, only 16 (26.6\%) teachers found it easier to teach Mathematics and Science in English. As seen in the table, the second item indicated negative perception where it shows the lowest mean score with 2.91. From the data shown in item 2, most of the younger teachers find it is tough for them to teach Mathematics and Science in English since Mathematics and Science course are taught in Bahasa Malaysia in IPGs. In the next item, 25 teachers agreed (16 teachers agreed and 9 teachers strongly agreed) to have fun in teaching Mathematics and Science using English. Since they believe that they had fun in teaching Mathematics and Science in English, the teachers felt that they must give exposure to the pupils in learning Mathematics and Science in English. This is proven when $66.7 \%$ (40) teachers believed that they are the one who is responsible to give them exposure. A total of $21(35 \%)$ teachers who were neither agree nor disagree that their pupils were having fun in learning.

\section{B. Teachers' perception on knowledge towards DLP}

Teachers have the perception that the effort done by our Education ministry had impacted them in a positive way. 46.7\% teachers agreed and $16.7 \%$ teachers strongly agreed that the courses that they attended had helped them in their teaching. Hence, the delivery of the knowledge by the teachers had proven the importance of DLP courses for the teachers. From the data shown, 45\% teachers agreed and 4.7\% strongly agreed that they had no hesitation in delivering knowledge to the pupils. Eventhough not all teachers are proficient in English, teachers had the effort to answer questions from pupils in English. 50\% (30) teachers agreed and $10 \%$ (6) teachers strongly agreed that they able to answer pupils' in English.
In addition to that, the notion of cultivating a growth mentality was found to be as important to the success of staff and teachers as it is to the students. Thus, $36.7 \%$ teachers agreed and $13.3 \%$ teachers strongly agreed that they realised the importance of discussion and collaboration in implementing DLP in their schools. The findings indicated that $19(31.7 \%)$ teachers agreed and $15(25 \%)$ teachers strongly agreed that they are ready to attend courses or workshop conducted by the ministry to enhance their skill or knowledge regarding DLP. Majority of the teachers agreed that they are confident enough to share about their knowledge about DLP to others.

\section{Factors affecting implementation of DLP}

\section{Questionnaire}

Pupils' ability was frequently chosen to be the factor that affects the implementation of DLP with $35 \%$. From the questionnaire give, it is a surprise that younger teachers aged between $25-30$ years old find that pupils ability as a challenge for them in implementing DLP in Mathematics and Science. Also, with $25 \%$ of teacher's vote, teachers' workload and time constrain was chosen to be the second factor that affects the implementation of DLP in Bintulu. Thirdly, the findings revealed that $20 \%$ of teachers felt that facilities, materials and resources prepared are not enough for them teach Mathematics and Science in English. Not only that, 11.7\% teachers stated that parents' encouragement was the factor that affects the implementation of DLP and followed by $8.3 \%$ teachers felt that teachers' lack of skill and confidence to be a factor that affects the implementation of DLP.

\section{Interview}

There are three main causes that were identified to be the factors that affects the implementation of DLP in Bintulu. English is a language that widely used especially in the fields of science and technology (Thelwal, 2019). Adding to that, science and technology are the main factors that drive the development of a country (Amankwah-Amoah, 2016). Not only that, mathematics is also one of the knowledge that closely associated with science in many aspects (Hallman-Thrasher et al., 2019). By realizing about the importance of English, it is believed that the ministry had decided to make a movement by teaching Mathematics and Science in English.

Most of the teachers that are teaching Mathematics and Science in English in Bintulu area believes that they are well-prepared in teaching. However, this study clearly shows that pupils are having difficulty in learning Mathematics and Science subjects in English. Most of them, especially the weaker once, could not understand instructions, textbook contents and what is being taught to them. With less understanding, pupils are not interested to learn. As a result, to that, teachers tried to help by switching languages to Bahasa Malaysia and even Bahasa Iban. When teachers started to translate to the pupils, they will depend more on the translation version and not English.

According to a Science teacher, the workload that a teacher has in school affects their teaching. It is a burden for teachers especially when they have to complete tasks given by the PPD 
or the school admin. Having too much school programmes is also affecting teachers in schools nowadays where they are the ones who are busy in the preparation.

It is also significant for teachers to be equipped with facilities and resources in teaching Mathematics and Science in English (Hooker, 2017). A mathematics teacher mentioned that it is time consuming in preparing teaching aids for teaching. A science teacher even bought own LCD to help the process of teaching and learning. Therefore, the ministry should find ways to have a comprehensive classroom. A science in Bintulu hopes that more interesting and hands-on resources will be prepared by the ministry which suites with the era of globalization.

\section{DISCUSSION AND CONCLUSION}

For several nations, English plays a major position as a second language, and it is important to have good command of English to reach higher education and decent employment (Hong, Chee \& Gunapathy, 2017). As the era is moving towards a rapid change towards globalisation, Science and Mathematics is also moving towards the world and technology (Vakil, 2008). Acquisition of English is therefore critical, because English is considered the universal language and language of information. Consequently, DLP implementation is in line with global growth and all improvements resulting from education policies are dictated by God, self, society and knowledge (Bullah \& Melor, 2018).

The purpose of this study was to investigate the perceptions of primary school teachers in Bintulu, Sarawak about the implementations of DLP. This study was also to identify the main factors that affects the implementation of DLP. In answering the first research question, 3 aspects that had been discussed; (1) Teachers' perception towards their interest, (2) Teachers' perception towards their skills, and (3) Teachers' perception towards their knowledge in DLP. In answering the second research question, three main factors were stated to be the main factors that were affecting the implementation of DLP; (1) Pupils' ability, (2) Workload and time constrain, and (3) facilities, resources and materials are not enough.

Teachers who were teaching DLP classes are found to be interested with the curriculum change. Even though the changes were made fast, they realised about the importance of preparing pupils for the future. They also understand that by having fun learning, pupils will be able to learn. Equally important to that is the skill of the teachers. Skills are meant to be gain from experience and they need time for results. Hence, the ministry should show more empathy and realise that teachers are doing their best in schools. Teachers' knowledge is another aspect that showed positive feedback. The teachers in schools are knowledgeable and they are able to deliver inputs. Thereupon, it is time for the community, parents and administrators to trust the deliverance.

In any implementations, there must be factors that might affect them. As for this study, pupils' ability was the biggest factor that are affecting the implementation of DLP.
However, teachers took this as a challenge and helped the pupils. The teachers also felt that workload and time constrain was one of the factor that affects the implementation of DLP. Unfortunately, this factor is not in controlled by them. Another factor that affects the implementation of DLP is the shortage of facilities, materials and resources.

\section{REFERENCES}

[1] Ah-Nam, L., \& Osman, K. (2017). Developing 21st century skills through a constructivist-constructionist learning environment. K-12 STEM Education, 3(2), 205-216.

[2] Amankwah-Amoah, J. (2016). The evolution of science, technology and innovation policies: A review of the Ghanaian experience. Technological Forecasting and Social Change, 110, 134-142.

[3] Arends, D., \& Kilcher, A. (2010). Teaching for student learning: Becoming an accomplished teacher. Routledge.

[4] Bada, S. O., \& Olusegun, S. (2015). Constructivism learning theory: A paradigm for teaching and learning. Journal of Research \& Method in Education, 5(6), 66-70.

[5] Bullah, N. H., \& Yunus, M. M. (2018, August). Dual Language Programme: Parent's Perception. In Proceedings of the 11th International Conference on Language, Education, and Innovation 2018, Singapore (pp. 11-12).

[6] Bullah, N. H., \& Yunus, M. M. (2018). Teachers' Perception on the Implementation of Dual Language Programme (DLP) in Urban Schools. Asian Social Science, 15(1), 24-31.

[7] Canales-Vela, V. (2017). Exploring Bilingual Teachers' Beliefs about Academic Language Development in Mathematics Teaching: Implications for Bilingual Teachers' Professional Development (Doctoral dissertation, The University of Texas Rio Grande Valley).

[8] Castleberry, A., \& Nolen, A. (2018). Thematic analysis of qualitative research data: Is it as easy as it sounds?. Currents in Pharmacy Teaching and Learning, 10(6) 807-815.

[9] Collier, V. P., \& Thomas, W. P. (2004). The astounding effectiveness of dual language education for all. NABE Journal of Research and practice, 2(1), 1-20

[10] Cheung, A. C., \& Slavin, R. E. (2012). Effective reading programs for Spanish-dominant English language learners (ELLs) in the elementary grades: A synthesis of research. Review of Educational Research, 82(4), 351-395.

[11] Cresswell, J. W., \& Plano Clark, V. L. (2011). Designing and Conducting mixed method research (2nd ed.). Thousand Oaks, CA: Sage.

[12] Czerniak, C. M., Weber Jr, W. B., Sandmann, A., \& Ahern, J. (1999). A literature review of science and mathematics integration. School Science and Mathematics, 99(8), 421-430.

[13] Etikan, I., Musa, S. A., \& Alkassim, R. S. (2016). Comparison of convenience sampling and purposive sampling. American journal of theoretical and applied statistics, 5(1), 1-4.

[14] Ertmer, P. A., \& Newby, T. J. (1996). The expert learner: Strategic, self-regulated, and reflective. Instructional science, 24(1), 1-24.

[15] Gill, S. K. (2012). The complexities of re-reversal of language-in-education policy in Malaysia. In English as an international language in Asia: Implications for language education (pp. 45-61). Springer, Dordrecht.

[16] Guiffrida, D. A. (2005). The emergence model: An alternative pedagogy for facilitating self- reflection and theoretical fit in counseling students. Counselor Education and Supervision, 44(3), 201-213.

[17] Hallman-Thrasher, A., Connor, J., \& Sturgill, D. (2019). Strong discipline knowledge cuts both ways for novice mathematics and science teachers. International Journal of Science and Mathematics Education, 17(2), 253-272.

[18] Hooker, M. (2017). A Study on the Implementation of the" Strengthening Innovation and Practice in Secondary Education Initiative" for the Preparation of Science, Technology, English and Mathematics (STEM) Teachers in Kenya to Integrate

[19] Information and Communication Technology (ICT) in Teaching and

[20] Learning (Doctoral dissertation, Queen's University Belfast).

[21] Honey, M., Pearson, G., \& Schweingruber, H. (Eds.). (2014). STEM integration in K-12 education: Status, prospects, and an agenda for research (Vol. 500). Washington, DC: National Academies Press.

[22] Hong, Y. C., \& Ganapathy, M. (2017). To Investigate ESL Students' Instrumenta and Integrative Motivation towards English Language Learning in a Chinese School in Penang: Case Study. English Language Teaching, 10(9), 17-35.

[23] Kelchtermans, G. (2005). Teachers' emotions in educational reforms Self-understanding, vulnerable commitment and micropolitical literacy. Teaching and teacher education, 21(8), 995-1006.

[24] Lim, C. P., \& Chai, C. S. (2004). An activity-theoretical approach to research of ICT integration in Singapore schools: Orienting activities and learner autonomy Computers \& Education, 43(3), 215-236.

[25] Lindholm-Leary, K., \& Hernández, A. (2011). Achievement and language proficiency of Latino students in dual language programmes: Native English speakers, fluent English/previous ELLs, and current ELLs. Journal of Multilingua and Multicultural Development, 32(6), 531-545.

[26] Ministry of Education. (2013). Malaysia Education Blueprint 2013-2025. Putrajaya.

[27] Nair, G. K. S., Setia, R., Mohamad, R., Kadir, Z. B. A., Luqman, A., Vadeveloo, T., \& Ngah, 
[28] H. C. (2014). Attitude, parental encouragement and perception of the importance of English in English language learning. Asian Social Science, 10(3), 1.

[29] Nasri, N. M., Yunus, S. M., \& Abdullah, S. I. S. S. (2018). Exploring Dual Language Program (DLP) Science Teachers' Perceptions and Experiences of Curriculum Change. International Journal of Academic Research in Progressive Education and Development, 7(4), 303-318.

[30] Nowell, L. S., Norris, J. M., White, D. E., \& Moules, N. J. (2017). Thematic analysis: Striving to meet the trustworthiness criteria. International Journal of Qualitative Methods, 16(1), 1609406917733847.

[31] Pandian, A., \& Ramiah, R. (2004). Mathematics and science in English: Teacher voice. The English Teacher, 33(11), 2004-50.

[32] Roberts, A. (2007). Global dimensions of schooling: Implications for internationalizing teacher education. Teacher Education Quarterly, 34(1), 9-26.

[33] Robertson, M., Line, M., Jones, S., \& Thomas, S. (2000). International students, learning environments and perceptions: A case study using the Delphi technique. Higher education research \& development, 19(1), 89-102.

[34] Smith, L. E., \& Nelson, C. L. (2019). World Englishes and issues of intelligibility The handbook of world Englishes, 430-446.

[35] Soulé, H., \& Warrick, T. (2015). Defining 21st century readiness for all students: What we know and how to get there. Psychology of Aesthetics, Creativity, and the Arts, 9(2), 178 .

[36] Suliman, A., Nor, M. Y. M., \& Yunus, M. M. (2017). Dual-Language Programme in Malaysian Secondary Schools: Glancing Through the Students' Readiness and Unravelling the Unheard Voices. GEMA Online® Journal of Language Studies, 17(4).

[37] Suliman, A., Nor, M. Y. M., \& Yunus, M. M. (2018). DUAL-LANGUAGE PROGRAMME (DLP) STUDENTS'LEVEL OF ENTHUSIASM AND CONFIDENCE: A PRELIMINARY STUDY. Teaching and Learning English in Multicultural Contexts (TLEMC), 2(1)

[38] Thelwall, M. (2019). Female Citation Impact Superiority 1996-2018 in Six Out of Seven English- Speaking Nations. Journal of the Association for Information Science and Technology.

[39] Ting, S. H. (2003). Impact of language planning on language attitudes: A case study in Sarawak. Journal of multilingual and multicultural development, 24(3), 195-210.

[40] Vakil, S. (2018). Ethics, identity, and political vision: Toward a justice-centere approach to equity in computer science education. Harvard Educational Review, $88(1), 26-52$

[41] Webb, T. L., Sniehota, F. F., \& Michie, S. (2010). Using theories of behaviour change to inform interventions for addictive behaviours. Addiction, 105(11), 1879-1892.

[42] Yunus, M. M., \& Sukri, S. I. A. (2017). The Use of English in Teaching Mathematics and Science: The PPSMI Policy vis-à-vis the DLP. Advances in Language and Literary Studies, 8(1), 133-142

\section{Audrey Shalini Ananthan}

Currently works as a teacher in one of the primary school in Malaysia. She also currently studies at Faculty of Education National University of Malaysia (UKM) 43600, Bangi, Selangor, Malaysia. She was awarded bronze medal for the innovation in the $1^{\text {st }}$ Creative and Innovative Teaching and Learning of Language (CINTELL) at Universiti Malaysia Pahang, Malaysia.

\section{Nur Ehsan Mohd Said}

$\mathrm{He}$ is a lecturer at Faculty of Education, National University of Malaysia. A few of his publication:

Recent research output:

(2019) Using Dictogloss Technique to Enhance Student's Skill in Writing Narrative Tex (2018) English Language Attitude: a case study of science stream and social science stream ESL learners

(2018) ESL Student's Perception of Teacher's Written Feedback Practice in Malaysian

Classrooms 